\title{
Rectal diazepam in the treatment of absence status: a pharmacodynamic study
}

\author{
NORMAN MILLIGAN,* SORAYA DHILLON, $\dagger$ ALAN RICHENS, $\dagger$ \\ JOLYON OXLEY
}

From the *Institute of Neurology, Queen Square, London, $†$ Department of Pharmacology and Materia Medica, Welsh National School of Medicine, Cardiff, and the $\ddagger$ Chalfont Centre for Epilepsy, Chalfont St Peter, Gerrards Cross, Bucks

SUMMARY Rectal administration of diazepam is highly effective in terminating absence status as judged by reduction of spike-wave activity in the EEG. Pharmacokinetic studies indicate that diazepam can have antiepileptic properties at serum levels well below those previously reported as being necessary to achieve a therapeutic effect.

Intravenous diazepam is regarded by most as the drug of first choice in the treatment of status epilepticus. ${ }^{2}$ Situations where facilities for intravenous administration are not available necessitate either an alternative route of administration of the same drug or an alternative therapy. For cases less extreme than tonic-clonic status, diazepam given via a route other than intravenous may be appropriate.

Pharmacokinetic studies have shown that absorption of diazepam following intramuscular injection is poor and erratic due to precipitation in the tissues ${ }^{3}$ and is related to the technique of administration. ${ }^{4}$ This route is therefore unsuitable when a rapid therapeutic effect is required. Rectal administration of diazepam solution in children produces peak serum concentrations within $10-20 \mathrm{~min}^{5}$ and is of value in preventing recurrent febrile convulsions. ${ }^{6}$ However, the use of such therapy in adults has been little explored. The value of this alternative route of administration of diazepam is illustrated in a patient prone to frequent absence status where quantification of spike-wave activity in the EEG provided an accurate assessment of a therapeutic response.

\section{Patient and methods}

The patient studied was a 35-year-old man, resident at the Chalfont Centre for Epilepsy, who has had epilepsy from the age of $2 \frac{1}{2}$ years. He suffered from tonic-clonic fits and frequent absences during which his EEG exhibited generalised atypical $2-2 \cdot 5 \mathrm{~Hz}$ spike-wave activity. The

Address for reprint requests: Dr N Milligan, Chalfont Centre for Epilepsy, Chalfont St Peter, Bucks SL9 0RJ, UK.

Accepted 21 July 1981 duration of his absences was highly variable and on occasions they were very prolonged lasting several hours. These were often succeeded by tonic-clonic seizures. EEG monitoring was achieved using the Oxford Medical Systems ambulatory EEG cassette tape recorder (Medilog 4) to which the patient was electively connected whilst well. This he wore continually, though not operating, until an absence status occurred. EEG monitoring was then initiated and treatment given under EEG control. The timing of equipment placement was aided by the clinical course of his epilepsy and the duration of the waiting period ranged from 1-7 days. On two occasions only was the equipment removed without the patient having an absence status.

During prolonged absences the following treatments were administered rectally on six occasions each: diazepam solution $(20 \mathrm{mg})$; diazepam suppository $(20$ $\mathrm{mg}$ ); saline. Diazepam (Valium, Roche) solution for intravenous injection and placebo (an equivalent volume of saline) were each injected into the rectum using a $5 \mathrm{ml}$ syringe to which was attached a plastic catheter lubricated with K-Y jelly. The suppositories were an experimental formulation having rapid release characteristics produced by Dr B Winsley, John Radcliffe Hospital, Oxford. Blood samples were withdrawn from an indwelling intravenous catheter at intervals over a 3 hour period for measurement of serum concentrations of diazepam. The procedure was identical for all treatments (including placebo) and the study was conducted single blind. Each taped EEG recording was subsequently coded and analysed blind. Ten min epochs of EEG ( 5 min either side of the blood sampling times) were written out on paper using the Oxford Medical Systems play back unit (PMD-12) connected to a 4 channel Mingograf ink-jet EEG recorder equipped with a high paper speed facility $(30 \mathrm{~cm} / \mathrm{s})$. Spikewave activity was quantitated by eye and the effectiveness of treatment was evaluated on the basis of the amount of 
spike-wave activity in each of the 10 min epochs of EEG after treatment compared to that in $10 \mathrm{~min}$ of control EEG before treatment. To obtain a detailed time-course of the onset of action of active treatment each tape was written out on paper continually from 0-30 min and divided into 1 min epochs, spike-wave activity being quantified and expressed as above. The control values were taken as $1 / 10$ th of the original $10 \mathrm{~min}$ control EEG.

The initial six active treatments were each preceded by a 3 hour placebo study in order to ensure that cessation of absences did not occur spontaneously. Thereafter, it became clear that the course of the type of absences under study was long and continuing. The remaining six active treatments were given only when it was felt that spontaneous cessation was unlikely as judged by continuance of fitting over a period of observation (usually more than 1 hour). The interval between active treatments ranged from 2-34 days (median 7 days) and the duration of the study was $6 \frac{1}{2}$ months. Chronic AED therapy was continued unchanged throughout. The significance of differences between treatments was determined using the MannWhitney $U$ test and differences between mean serum diazepam concentrations were assessed using Student's $t$ test.

\section{Resulis}

Figure 1 shows the results of the spike-wave analysis over a 3 hour period. Both active treatments markedly reduced spike-wave activity, diazepam solution having a more dramatic effect. Unlike the suppository, the effect of the solution tended to wane after $90 \mathrm{~min}$ although the values were still significantly different from placebo (table).

Changes in spike-wave activity following both active treatments reflected differences in the rate of rise of diazepam serum concentration (nig 2). The mean serum level at $15 \mathrm{~min}$ after the solution was 194 $\mathrm{ng} / \mathrm{ml}(\mathrm{SD} \pm 66 \mathrm{ng} / \mathrm{ml})$ compared to $58 \mathrm{ng} / \mathrm{ml}$ $(\mathrm{SD} \pm 19 \mathrm{ng} / \mathrm{ml})$ after the suppository $(\mathrm{p}<0.01)$. Peak serum levels were higher and attained more rapidly after solution (mean $323 \pm 107 \mathrm{ng} / \mathrm{ml}$ at 50 min) than after suppository (mean $257 \pm 50 \mathrm{ng} / \mathrm{ml}$ at $58 \mathrm{~min}$ ) though differences were not significant. The mean serum level at $180 \mathrm{~min}$ after the solution $(142 \pm 28 \mathrm{ng} / \mathrm{ml})$ was significantly lower than after suppository $(177 \pm 33 \mathrm{ng} / \mathrm{ml})(\mathrm{p}<0.05)$ and this corresponded to a significant increase in spike-wave

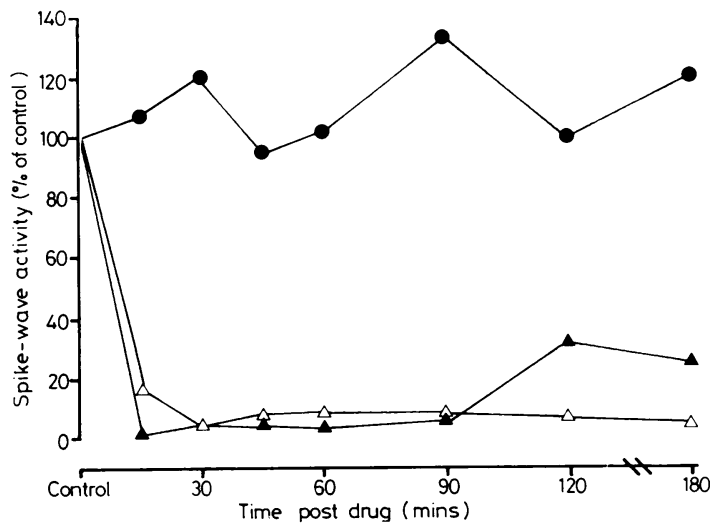

Fig 1 Results (means of six treatments) of spike-wave analysis over a $3 \mathrm{~h}$ period after rectal administration of saline ( $\bullet \bullet)$, diazepam solution $20 \mathrm{mg}(\boldsymbol{\Delta}-\mathbf{\Delta})$ and an experimental diazepam suppository $20 \mathrm{mg}$ $(\triangle \longrightarrow \triangle)$. Assessment was by counting spike-wave activity in 10 min of control EEG and in seven 10 min periods following treatment (5 min either side of times shown). Differences from saline $(p<0.01)$ except at $120 \mathrm{~min}$ after diazepam solution $(p<0.05)$. Differences between diazepam solution and diazepam suppository at $15 \min$ and $180 \min (p<0.05 ;$ Mann-Whitney $U$ test $)$.

activity ( $p<0.05)$. Differences among serum concentrations at other times were not significant.

As shown in fig 3, both active treatments produced an effect much earlier than $15 \mathrm{~min}$. Reduction of spike-wave activity occurred within the first $5 \mathrm{~min}$, differences between treatments becoming significant at $8 \mathrm{~min}$ and persisting until $16 \mathrm{~min}(\mathrm{p}<0.05)$. Figure 4 shows the same data with serum levels emphasising the relationships between rate of change in serum concentration and reduction of spike-wave activity. Following diazepam solution, spike-wave activity fell to $46 \%$ of the control at 5 min (mean serum level $30 \pm 15 \mathrm{ng} / \mathrm{ml} ; \mathrm{n}=3$ ). A comparable serum concentration was achieved at 10 min after the suppository (mean $34 \pm 21 \mathrm{ng} / \mathrm{ml}$ ) when spike-wave activity was reduced to $24 \%$ of the control. Clearly an effect was evident before this time at which point serum levels would have been lower (mean at $5 \mathrm{~min}$ $18 \pm 11 \mathrm{ng} / \mathrm{ml})$.

Table Spike-wave activity (mean $\pm 1 S D$ ) in seconds before and after rectal administration of saline and diazepam. Differences from saline $(p<0.01)$ at all points except ${ }^{*}(p<0.05)$; Mann-Whitney U test $)$.

Differences between diazepam solution and diazepam suppository $+(p<0.05 ;$ Mann-Whitney $U$ test $)$. Statistics were done using percentage data

\begin{tabular}{|c|c|c|c|c|c|c|c|c|}
\hline & Control & $10-20 \mathrm{~min}$ & $25-35 \mathrm{~min}$ & $40-50 \mathrm{~min}$ & $55-65 \mathrm{~min}$ & $85-95 \mathrm{~min}$ & $115-125 \mathrm{~min}$ & $175-185 \mathrm{~min}$ \\
\hline Saline & $371 \pm 69$ & $398 \pm 163$ & $446 \pm 171$ & $347 \pm 169$ & $375 \pm 204$ & $489 \pm 124$ & $368 \pm 229$ & $443 \pm 175$ \\
\hline Diazepam suppository $(20 \mathrm{mg})$ & $418 \pm 155$ & $67 \pm 36$ & $17 \pm 24$ & $30 \pm 39$ & $32 \pm 48$ & $29 \pm 47$ & $23 \pm 34$ & $18 \pm 16$ \\
\hline Diazepam solution $(20 \mathrm{mg})$ & $537 \pm 26$ & $+8 \pm 13$ & $24 \pm$ & $23 \pm$ & $14 \pm$ & $26 \pm$ & $* 164 \pm 157$ & $\dagger 130 \pm 131$ \\
\hline
\end{tabular}




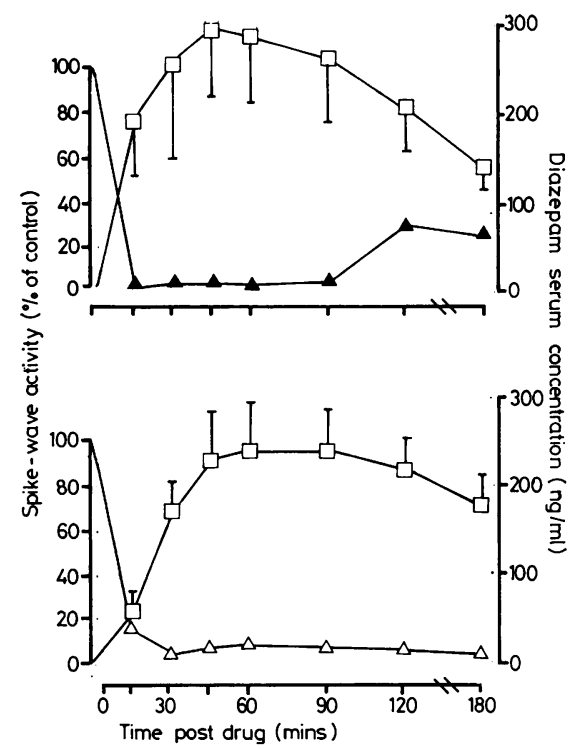

Fig 2 Spike-wave activity with serum levels of diazepam (means of six treatments) after diazepam solution $20 \mathrm{mg}$ (top) and diazepam suppository $20 \mathrm{mg}$ (bottom). Mean serum levels $(\square-\square)$ at $15 \mathrm{~min}$ and $180 \mathrm{~min}$ significantly different $(p<0.01$ and $p<0.05$ respectively; unpaired $\mathrm{t}$ test). The lower mean serum concentration at 180 min after diazepam solution coincided with a significant increase (top) in spike-wave activity $(p<0.05 ;$ Mann-Whitney $U$ test $)$.

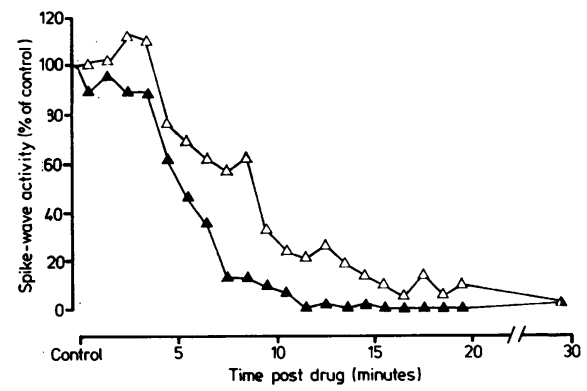

Fig 3 Spike-wave activity (means of six treatments) in 1 min epochs from 0-30 min each expressed as a \% of the control. The control was 1/10 of the original $10 \mathrm{~min}$ control EEG. Diazepam solution $(\Delta-\mathbf{\Delta})$ was superior to the suppository $(\triangle \longrightarrow \triangle)$ in reducing spike-wave activity between 8 and $16 \min (p<0.05$; Mann-Whitney U test).

\section{Discussion}

Absence seizures have a reputation for being particularly sensitive to benzodiazepines, intravenous diazepam being effective in $93 \%$ of cases of absence status compared to $88 \%$ of tonic-clonic

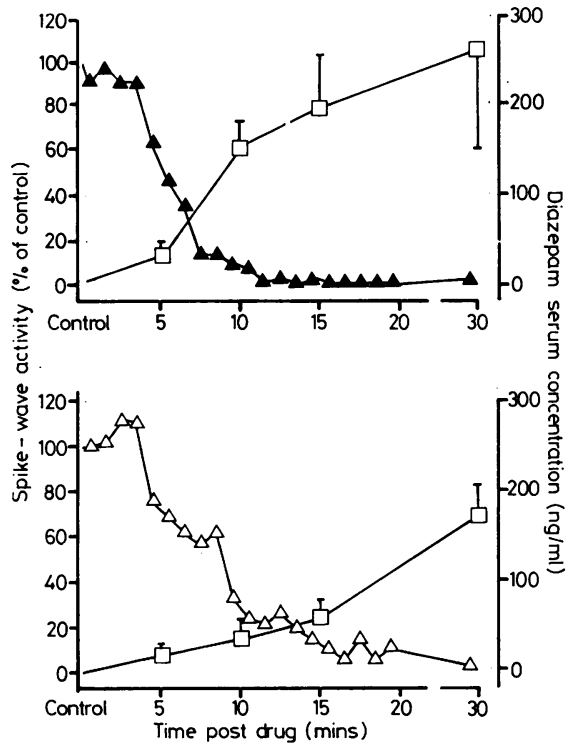

Fig 4 Spike-wave activity 0-30 min with serum concentrations of diazepam ( $\square-\square$ ) following the $20 \mathrm{mg}$ solution (top) and the $20 \mathrm{mg}$ suppository (bottom). Serum levels are mean values (diazepam solution $5 \min n=3 ; 10 \min n=4 ;$ others $n=6)$. Differences between mean serum levels $(p<0.01$; unpaired $\mathrm{t}$ test ).

status and $75 \%$ of complex partial status. ${ }^{2}$ These results show that rectal administration of diazepam, either as a rapid release suppository or as a solution, is highly effective in terminating absence status as judged by reduction of spike-wave activity in the EEG. Pharmacokinetic studies indicate that diazepam solution is rapidly absorbed from the rectum and an antiepileptic effect is evident within $5 \mathrm{~min}$. Serum concentrations of $\mathrm{N}$-desmethyldiazepam were negligible indicating that the results were not due to a cumulative effect. Diazepam suppositories provide a more convenient mode of administration but serum levels are lower and rise more slowly than after an equivalent dose of the solution even with the rapid release formulation used. It should be noted that the wax-based suppositories now commercially available (Valium, Roche) are very slowly absorbed and are unsuitable for clinical use when a rapid therapeutic effect is required.

Administration of both agents per rectum to volunteer patients with epilepsy show marked variations in serum diazepam levels achieved between subjects (Dhillon et al, unpublished) and this may prove a limiting factor in their use. The bioavailability of diazepam solution given rectally is almost complete, ${ }^{7}$ although others express a more conservative estimate and suggest that adsorption to 
faeces or loss of the drug through the anus may account for incomplete absorption. ${ }^{3}$ The serum level of diazepam required to achieve an antiepileptic effect is uncertain, however, and interpretation of serum levels achieved is difficult as the benzodiazepines are lacking a well established therapeutic range. The minimum effective serum concentration has been variously estimated, values between $150-500$ $\mathrm{ng} / \mathrm{ml}$ being suggested as therapeutic, ${ }^{8-10}$ although the methods of determination are open to criticism. Such estimates have often been based on recurrence of seizures or interictal epileptiform abnormalities in the EEG following initial suppression with intravenous diazepam. The results of our study show that diazepam can have antiepileptic properties at serum levels well below those previously reported. However, there was no clear relationship between therapeutic effect and serum concentration. The point at which spike-wave activity reappeared occurred at serum levels well above those necessary to induce an effect. It is perhaps the rate of increase in serum concentration, and therefore rapid penetration into the brain, which is more important than the concentration per se. Previous estimates of a minimum effective serum concentration based on recurrence of EEG abnormalities may therefore not be truly representative. Evaluation of the subjective sedative effects of the drug in other studies ${ }^{11} 12$ tend to support this view. Our results, however, are limited in that this is a single case study. The difficulties in obtaining pharmacodynamic data during clinical seizures are self evident. Whether this form of treatment will be of value to other patients with different seizure types requires further work. Studies along these lines are in progress.

The authors are grateful to Dr B Winsley, John Radcliffe Hospital, for supply of diazepam suppositories.

\section{References}

${ }^{1}$ Mattson RH. The benzodiazepines. In: Woodbury DM. Penry JK, Schmidt RP, eds. Antiepileptic Drugs. New York: Raven Press, 1972.

${ }^{2}$ Browne J, Penry JK. Benzodiazepines in the treatment of epilepsy. Epilepsia 1973;14:277-310.

${ }^{3}$ Magnusson I, Oxlund HRW, Alsbirk KE, Arnold E. Absorption of diazepam in man following rectal and parenteral administration. Acta Pharmacol Toxicol (Kbh) 1979;45:87-90.

- Gamble "JAS, Dundee JW, Assaf RAE. Plasma diazepam after single dose oral and intramuscular administration. Anaesthesia 1975;30:164-9.

${ }^{5}$ Knudsen FU. Plasma diazepam in infants after rectal administration in solution and by suppository. Acta Paediat Scand 1977;66:563-7.

${ }^{6}$ Knudsen FU. Rectal administration of diazepam in solution in the acute treatment of convulsions in infants and children. Arch Dis Child, 1979;54:855-7.

' Moolenaar F, Bakker S, Visser J, Huizinga $T$. Biopharmaceutics of rectal administration of drugs in man 1X. Comparative biopharmaceutics of diazepam after single rectal, oral, intramuscular and intravenous administration in man. Int $J$ Pharmaceut 1980;5:127-37.

${ }^{8}$ Viala A, Cano JP, Dravet C, Tassinari CA, Roger J. Blood levels of diazepam (Valium) and N-desmethyldiazepam in the epileptic child. Psychiatr Neurol Neurochir 1971;74:153-8.

- Booker HE, Celesia GG. Serum concentrations of diazepam in subjects with epilepsy. Arch Nelirol 1973;29:191-4.

10 Agurell S, Berlin A, Ferngren H, Hellstrom B. Plasma levels of diazepam after parenteral and rectal administration in children. Epilepsia 1975;16:277-83.

11 Bliding A. Effects of different rates of absorption of two benzodiazepines on subjective and objective parameters: significance for use and risk of abuse. Eur J Clin Pharmacol 1974;7:201-11.

12 Kanto J. Plasma concentrations of diazepam and its metabolites after peroral, intramuscular and rectal administration. Int J Clin Pharmacol 1975;12:427-32. 